\title{
Editorial
}

\section{Obesity: A Growing Problem in China}

\author{
Chengjun Sun, PhD*
}

School of Management and Economics, Kunming University of Science and Technology, 253, Xuefu Road, Kunming, Yunnan 650093, China

\section{${ }^{*}$ Corresponding author}

Chengjun Sun, PhD

Assistant Professor, School of Management and Economics, Kunming University of Science and Technology, 253 Xuefu Road, Kunming, Yunnan 650093, China

E-mail: cjunsun@gmail.com

\section{Article information}

Received: April 19th 2018; Accepted: April 19 th $^{\text {th }}$ 2018; Published: April 19th 2018

\section{Cite this article}

Sun C. Obesity: A growing problem in China. Obes Res Open J. 20I8; 5(I): el-e2. doi: 10.17140/OROJ-5-e0I3

$\mathrm{O}$ besity is defined as excessive body fat accumulated to the extent that presents a risk to health. A measure of obesity is the body mass index (BMI), a person's weight (in kilograms) divided by the square of the person's height (in meters). A person with a BMI of 30 or over is generally considered obese, and a BMI of 25 or over considered overweight. ${ }^{1}$

Obesity is a major risk factor for chronic diseases, including diabetes, cardiovascular diseases and cancer. Obesity also damages productivity. Obese people move slower and are sick from work more often due to complications of diabetes and other noncommunicable diseases (NCDs). Obesity was once considered a problem only in high-income countries, and now, however, it is dramatically increasing in developing countries. ${ }^{1}$ Unfortunately, at present, nearly one-third of the world's population is obese or overweight, i.e., 2.1 billion. $^{2}$

The World Health Organization (WHO) predicts that even though undernutrition and infectious diseases dominate the current public health concerns, obesity would soon become the most significant cause of poor health. ${ }^{3}$ In China, $10.8 \%$ of men and $14.9 \%$ of women of 1.4 billion people are overweight by 2016 , which is the largest number of overweight people in the world. ${ }^{4}$ China's obesity has outpaced the economic growth. Beside urban areas, obesity rates in rural China are skyrocketing. For instance, in rural Shandong province, the rate of obese and overweight boys jumped from $0.5 \%$ in 1985 to $30.7 \%$ in 2014; in girls, the percentage increased from $0.8 \%$ to $20.6 \%$ over the same period. ${ }^{5}$ But what in fact leads to the sudden increase? Three main factors are listed below.

- High-energy Western diet: fast food, soft drink, sugar offerings (KFC, McDonald's, Starbucks, etc.);
- De-emphasis on sports and more time behind computer and television screens;

- Overfeeding children with rising disposable incomes.

Obesity is a public health problem considering its prevalence, costs, and health effects. Funding, innovation and an understanding the link to overnutrition are key elements in winning the battle. $^{6}$ Governments should take the lead in dealing with obesity problems. Regulations against related advertisements should be enacted; national tax can be implemented on certain products (e.g., soft drinks and processed food) to reduce consumption; awareness about healthy eating, exercise and the danger of obesity should be promoted; and all related institutions should get involved.

\section{ACKNOWLEDGEMENT}

The author acknowledges financial support from the project of KMUST for Fostering Talents in provincial level (KKSY20160 8050) and the project of Yunnan Education Department (2016ZZX055). The author would like to acknowledgement Kunming University of Science and Technology research facility and support.

\section{REFERENCES}

1. Wikipedia. Obesity. Web site. https://en.wikipedia.org/wiki/ Obesity. Accessed April 18, 2018.

2. Chung C. Obesity and malnutrition: Two sides of one crisis. News Deeply. 2017. Web site. https://www.newsdeeply.com/ malnutrition/articles/2017/12/15/obesity-and-malnutrition-twosides-of-one-crisis-2. Accessed April 18, 2018. 
3. World Health Organization. Obesity: Preventing and managing the global epidemic (Report). 2000. Web site. http://www.who. int/nutrition/publications/obesity/WHO_TRS_894/en/. Accessed April 18, 2018.

4. Global Times. According to a new study, China is now home to the greatest number of obese people on Earth - what that means for its present and future. 2016. Web site. http:/ /www.globaltimes. cn/content/977264.shtml. Accessed April 18, 2018.
5. Match C. Obesity rates skyrocket in China's rural kids. Science. 2016. Web site. http://www.sciencemag.org/news/2016/04/obesity-rates-skyrocket-china-s-rural-kids. Accessed April 18, 2018.

6. Satcher D. The Surgeon General's Call to Action to Prevent and Decrease Overweight and Obesity. U.S. Dept. of Health and Human Services, Public Health Service, Office of Surgeon General. 2001. Web site. https://www.cdc.gov/nccdphp/dnpa/pdf/CalltoAction.pdf. Accessed April 18, 2018. 